\title{
ENSAIO BIBLIOGRÁFICO ALGUMAS FACES DE OUTROS EUS. HONRA E PATRONAGEM NA ANTROPOLOGIA DO MEDITERRÂNEO*
}

Ana Claudia D. R. Marques

GELLNER, Ernest \& WATERBURY, John (orgs.). 1977. Patrons and Clients in Mediterranean Societies. London: Duckw orth/Center for Mediterranean Studies of the American Universities Field Staff.

HERZFELD, Michael. 1987. Anthropology Through the Looking Glass. Critical Ethnography in the Margins of Europe. New York/Cambridge: Cambridge University Press.

PERISTIANY, J. G. (org.). 1974 [1966]. Honour and Shame. The Values of Mediterranean Societies. Chicago: The University of Chicago Press.

I.

De quem são os traços que um artista revela e esconde em sua obra? O pintor, seus modelos, seus respectivos mundos, não se despem, cada um a seu modo, nas mesmas pinceladas? $\mathrm{Na}$ antropologia não parece ser muito diferente: construímos nosso mundo, nossos mitos e valores na mesma medida em que procuramos desenhar os de nossos nativos, como já nos apercebemos vezes sem conta. A antropologia do M editerrâneo é um campo fecundo para a compreensão do processo de produção de contornos, por vezes demasiado rígidos, de nossos sujeitos. Tomar estereótipos por princípios explicativos é um risco persistente no mediterranismo e nos campos de estudo que inspirou, como sucedeu na antropologia brasileira a partir da década de 70. M as o problema é bem mais geral; permanece presente e é extensível a toda a antropologia. Eis porque vale a pena retornar a alguns textos, hoje clássicos, que tiveram importância decisiva na constituição de uma antropologia sobre o M editerrâneo.

A identificação de atributos distitivos das sociedades mediterrânicas não deve ser desvinculada do deslocamento rumo à periferia de uma região que já ocupou posição central no universo político, econômico e cultural. A o identificarmos esse mundo com os valores de honra, com a violência ou com o clientelismo, geramos outros qualificativos que defi- 
nem, por contrapartida, os atuais ocupantes do centro. $M$ as aquilo que revelamos de nós e dos outros, o modo como o fazemos, os processos e condições implicados não são sempre evidentes.

As relações entre regra e prática, teoria e etnografia, ciência e senso comum, entre outras, no modo como são abordadas em A nthropology Through the Looking Glass, por M ichael Herzfeld, constituem desdobramentos destes vel hos problemas. Cada um dos termos destas relações supõe o seu par, não necessariamente como um oposto. Herzfeld procura romper com a diferença de nível, de caráter hierárquico, com que são usualmente tratados esses termos, equiparando-os, ambos, e o dualismo que conceptualmente constituem, enquanto fenômenos sociais. Neste trabalho, estas relações são pensadas mediante a abordagem do material etnográfico concernente à Grécia moderna, o que não é casual. A posição marginal da Grécia do ponto de vista político, acadêmico e etnográfico - várias faces do mesmo fenômeno - fornece-lhe o subsídio para tratar o problema; constitui, como diz, um espelho para o antropólogo (:25).

A temática do livro, só imperfeitamente sintetizada aqui, é muito vasta. A pesar de supor um árduo esforço analítico, o trabalho de Herzfeld inspira exercícios mais simples ou voltados para assuntos mais específicos. Seguindo trilhas traçadas ou sugeridas por sua análise, proponho aqui refletir sobre possíveis pressupostos, nem sempre explícitos, em abordagens antropológicas dos valores de honra e da patronagem, assuntos também correlacionados à antropologia do M editerrâneo, a exemplo daqueles privilegiados por Herzfeld. Trata-se de ressaltar a importância de idéias, val ores, condições sociais, políticas, materiais etc., que fazem parte de nosso mundo como condição de produção de conhecimento e, portanto, da inclusão inevitável da situação do antropólogo nas suas formulações conceituais.

Esses assuntos específicos são contemplados por Herzfeld mais ou menos detidamente em Anthropology Through the Looking Glass e retornam, sobretudo aquele dos valores de honra e vergonha, em vários outros trabalhos. Para lidar com essa "cosmologia" do pensamento antropológico recorrerei a ensaios de diversos autores, publicados nas coletâneas Patrons and Clients e Honour and Shame. Essas obras, referências importantes da Antropologia do M editerrâneo, resultaram de encontros acadêmicos explicitamente voltados a temáticas comuns, ou análogas em algum grau, a diversas sociedades espal hadas por uma vasta área geográfica. A quase totalidade das contribuições reunidas em Patrons and Clients é constituída de artigos escritos à luz de discussões ocorridas em um seminário organizado por Gellner, em 1974, sobre o tema das mudan- 
ças nas formas de patronagem em sociedades mediterrânicas, provocadas por processos de industrialização, urbanização ou secularização (1977: X). No livro se expressa uma preocupação de reunir trabalhos centrados em material etnográfico de procedência muito diversa. Ao longo de suas páginas, vão sendo apresentadas características sociais, políticas, econômicas ou religiosas específicas de sociedades situadas em uma área que circunda todo o M editerrâneo, incluindo Península Ibérica, Sul da Europa, os antigos Estados socialistas do Leste da Europa, países do Oriente Médio e do Norte da África.

Peristiany, organizador de Honour and Shame, não demonstra a mesma preocupação em representar sociedades tão variadas e numerosas. Em contrapartida, os seis ensaios reunidos nessa obra são genericamente mais longos e discutem de forma mais minuciosa questões reunidas sob o tema comum de um certo complexo de valores culturais que se entendeu ser característico de sociedades mediterrânicas. Na sua maior parte, os autores participaram de todas as três conferências ocorridas em 1959, 1961 e 1963, programadas com o propósito de discutir o mesmo assunto.

Embora as contribuições reunidas nessas duas obras sejam utilizadas aqui, em parte, como material problematizado sob a inspiração de uma obra bem mais recente, como a de Herzfeld, não pretendo sugerir que elas expressem pensamentos em estado bruto, mais tarde refinados teoricamente. A o contrário, há um claro cuidado crítico concernente à abordagem de temáticas mediterranistas, perceptível em artigos e presidindo a própria organização tão pluralista dessas obras. Considero manifestações dessa dimensão crítica as definições problemáticas das fronteiras de seus objetos, a reunião de diversas perspectivas - moral, política, histórica, econômica etc. - com que são tratados, a recusa de definições já consolidadas de relações e de valores e, ainda, a cautela em evitar generalizações relativas ao estabelecimento de um corpo de saber concernente à área cultural mediterrânea. Tomo-os, portanto, como textos criteriosamente elaborados e discutidos e, nestas condições, abordo-os de modo a perceber neles a seleção de pressupostos que compõem a tal cosmologia antropológica.

\section{II.}

Como um neófito recém-ingresso em uma confraria, somos rapidamente informados da importância do outro em nossa disciplina, quando ainda ensaiamos nossos primeiros passos na academia. A prendemos, sob esse 
pretexto, a distinguir certas condições históricas fundamentais à emergência da antropologia, consoantes com fatores não menos relevantes relacionados ao desenvolvimento do pensamento científico. Se fizermos digressões até os descobrimentos e os relatos dos missionários, vemos como o "bom selvagem" e o "lobo do homem" cedem rapidamente lugar ao "primitivo", categoria tampouco imune a julgamentos de valor.

Reconhecida a nossa triste condição de tributários da opressão e do preconceito, segue-se a revelação - que é já uma punição - do caráter trágico da disciplina: seu objeto, à custa das atitudes em relação a ele, do que não se dirime o próprio antropólogo, está no fim. As sociedades primitivas foram desaparecendo na mesma medida em que se foi constituindo um saber acerca delas; a antropologia é quase natimorta. Para aliviar tamanho mal-estar entre os neófitos, um recurso de redenção. $O$ outro não precisa ser tão primitivo, nem tão distante - muito embora tenha de preservar um pouco de ambas as qualidades. Mal ou bem, não obstante todas as vicissitudes e todos os vícios, constituiu-se um campo de conhecimento passível de absorver novos objetos não previstos antecipadamente.

Do mato para o campo e para a cidade, a constituição dos nativos enquanto tais resulta antes da atitude dos cientistas do que dos supostos atributos dos primeiros. A aproximação do outro parece ter-se dado sempre a par de uma progressiva concessão, por parte dos antropólogos, de atributos de sujeito a seu objeto, em contrapartida a uma também progressiva (má) consciência de si. Se a eventual consciência do próprio poder de nossos ancestrais fundadores não lhes ruborizava as brancas faces, os seus descendentes não desfrutaram da mesma leveza de espírito.

A aproximação do outro, e por conseguinte a conservação da alteridade através de um distanciamento metodológico ou teoricamente distinto, não exclui uma relação de forças intrinsecamente envolvida na constituição de nosso objeto, mesmo que definido enquanto sujeito, porque é necessariamente outro. Possivelmente essas formas fiquem tanto menos perceptíveis quanto mais as aproximamos de nós. Tem-se mostrado mais fácil expiar a culpa dos agentes coloniais, que não deixamos de ser, do que notar o quanto projetamos de nós mesmos naqueles de quem nos aproximamos. E, ironicamente, o movimento tem duplo sentido, já que tais elaborações acerca do outro supõe essencial izações acerca de nós mesmos.

A relação de alteridade pode traduzir-se num jogo de graduação variável de semelhanças e diferenças, sempre em relação a um ego, medida de todas as coisas. É através dele que um aborígene australiano tanto pode estar no limiar da humanidade com a animalidade quanto 
dispor de estruturas inconscientes das quais partilha toda a humanidade; causar horror por seus atavismos ou admiração pela sofisticada relação que estabelece com seu ambiente. Do mesmo modo, nosso vizinho, alguém que quase não notamos, mas com o qual partilhamos muitas características, pode ser subitamente convertido em um estranho digno de todo interesse analítico. Isso não se distingue muito do que veio a acontecer quando a antropologia incorporou novos objetos, desde certo ponto de vista mais familiares, ao seu rol ameaçado de desgaste. Incorporação que implica sempre atribuição, ou exaltação, por conseguinte valoração, de diferença, que já se insinua no próprio ato de determinação do vizinho a ser analisado, que não é em si outro, nem casual mente eleito.

III.

A seleção do objeto, ou melhor, a sua elaboração, transporta consigo elementos dificilmente depuráveis no trabalho analítico, uma vez que fazem parte da sua própria definição. Assim, um processo de essencialização se faz presente desde o ponto de partida das investigações, tanto na adoção quanto na recusa de objetos, o que vai interferir nas análises subseqüentes. Herzfeld (1987) relaciona a ambigüidade da situação da Grécia moderna, uma espécie de posto avançado do Oriente mergulhado no próprio berço da civilização européia, símbolo de contaminação e de pureza ao mesmo tempo (e suas ambigüidades estão longe de serem encerradas aí) ao teimoso desinteresse demonstrado pelos antropólogos a seu respeito. $M$ ais que isso, assume essa ambigüidade como meio de evitar sucumbir às essencializações que entende ser um produto de um sistema simbólico dos antropólogos, não menos merecedor de nossa atenção do que outros mais tradicionalmente estudados em nossa disciplina. Um sistema que é exposto à luz por Herzfeld justamente através da sua etnografia sobre a Grécia moderna. Suas já referidas especificidades justificam a empresa, mas a problemática é extensível a toda a chamada Antropologia do Mediterrâneo, das margens da Europa, onde florescem esses outros paradoxais, essência e antítese de nós mesmos, nossos primitivos no duplo sentido de origem e de rudimentar. Com efeito, as observações de Herzfeld abrem caminho para que temas tradicionais sejam de novo abordados, com renovada inspiração.

As etnografias em comunidades do Sul da Europa, Norte da África e Oriente Próximo, avolumadas sobretudo desde os anos 60, vieram alimentar, dado o conjunto considerável de características comparáveis de 
várias daquelas sociedades, uma concepção de área cultural e de uma Antropologia do M editerrâneo. Destaca-se, a esse propósito, a centralidade de algo que foi compreendido como um valor cultural, o par honra e vergonha, que orientaria as condutas individuais nessas comunidades, chegando mesmo a fornecer o nexo conformador de coletividade a esses grupos e sustentando, na qualidade de um sistema moral, relações pessoais de características marcadamente frouxas do ponto de vista formal ou institucional (Pitt-Rivers 1974 [1966]:22). As relações de amizade, patronagem e compadrio, tal como os "valores" de honra e de vergonha aos quais estão articuladas, não são exclusivamente mediterrâneas, já que estão presentes um pouco por toda parte. Contudo, constituem um outro fator recorrente que ajudou a conferir o traço de diferenciação da área cultural.

Cabe notar que o desenho dessa "área" não se fez irrefletidamente. Pautados em estudos etnográficos, os antropólogos logo notaram, e muito claramente, a importância das variantes locais e há que se mencionar a cautela e a reserva muitas vezes demonstradas com relação a toda atitude intelectual de homogeneização analítica de um campo cultural tão rico'. M as essa resistência não exclui a tentação sempre presente de chegar a um mínimo denominador comum, abstração mais portátil, por assim dizer, nem sempre tão refletida. A depuração dos elementos locais pode ser um subproduto indesejável da própria tradução de termos nativos para a língua do antropólogo, problema antigo da disciplina ao qual retornou Herzfeld (1980)2. De todo modo, as simplificações são compreensíveis não só porque o desconforto causado pela multiplicação das variações é considerável, como também a recusa das abstrações tem como limite o próprio reconhecimento daquelas constatações iniciais de um fundo comum partilhado pelos elementos de um conjunto, definido como área cultural. O mediterranismo, como notou Herzfeld, é expressão concreta do dilema do antropólogo, que se encontra entre o risco de produzir uma caricatura em virtude de sua insistência em ajustar particularidades a um único quadro de análise e o de desintegrar este quadro, caso privilegie as particularidades (1984:446).

De modo similar, também constatamos esforços no sentido de dar unidade ao conjunto das particularidades etnográficas concernentes às discussões sobre patronagem, dificilmente redutíveis a um equivalente comum, não obstante partil harem várias características. N este caso, as variações parecem aproximar-se efetivamente do limite de possibilidade de configuração de um objeto único: os diversos colaboradores de Patrons and Clients, apoiados em suas experiências etnográficas, obrigaram-se a 
explicitar o que entendem por "patronagem" ou por relações "patrãocliente", observação aliás problematizada ali por Gilsenan (:167) e também aludida por Waterbury (:341). Depreende-se do conjunto dos trabaIhos uma referência a um corpo abstrato de definições do qual os casos particulares se afastam sempre, por excesso ou por carência de elementos. A os contornos, variáveis, dessas relações confere-se estatutos teóricos distintos nas diferentes análises ${ }^{3}$. Por outro lado, os campos semânticos locais apreensíveis para categorias como patrão e cliente, ou honra e vergonha, também variam. Com efeito, parece que tais termos tendem a acumular significados distintos onde quer que adquiram uma relevância cultural mais acentuada (cf. Gellner 1977:1). A eles se associam, correspondentemente, valores também variáveis ${ }^{4}$. No que concerne aos valores de honra, a multiplicidade de sentidos concorrentes é notavelmente ilustrada nos ensaios reunidos em Honour and Shame. Pitt-Rivers e Baroja, por exemplo, mostram como os códigos de apreciação moral das condutas se modificam conforme a classe social dos sujeitos e no tempo, respectivamente. A referência a um código de honra alimentado por tradições distintas, como a cristã e a de pastores gregos, conforme faz Campbell, e a margem de flexibilidade que permite aos sujeitos o acionamento, em proveito próprio, de elementos do código de honra de sua cultura, percebida por Bourdieu, são abordagens que evidenciam ainda mais claramente as indeterminações, ambigüidades, multiplicidades semânticas envolvidas na vida social.

Toda tentativa de converter relações vividas em categorias deslocadas de seus contextos etnográficos corre o risco de um esvaziamento semântico. Além disso, essas operações analíticas bem podem conferir novos significados, ou reificar alguns dos localmente existentes em detrimento de outros (cf. Herzfeld 1980; 1984; 1985). Tudo se complica ainda mais se pensarmos como é difícil evitar a atribuição de significados prévios a situações desconhecidas - procedimento que sequer é apanágio da atividade acadêmica. Dispondo de um conceito analítico bem delineado, é fácil projetá-lo quase mecanicamente em uma realidade em que a priori, não podemos assegurar que esteja. Ao ouvir designações nativas de "patrão" ou de "honra", já nos sentimos tentados a fazer as derivações a que estamos acostumados.

Silverman (1977) salienta os efeitos da confusão entre perspectivas locais e acadêmicas acerca do termo patrão, que borra a distinção entre o produto da abstração operada pelos pesquisadores a partir dos comportamentos observados e as construções também abstratas dos próprios nativos - duas mitologias se misturam. De algum modo antecipa Herz- 
feld (1987), ao assinalar que os nativos também essencializam suas perspectivas acerca da realidade que vivem, adicionando valores a tais construções. Estas “ideologias", nota ela, possuem existência em si mesmas; são observáveis em seu uso, na sua conversão em idioma nas interações sociais (1977:11-12). A confusão entre construções analíticas e nativas congela, portanto, toda uma dimensão retórica. Recorrendo ao argumento de Herzfeld (1987:95 e ss.), é como se perdêssemos de vista o caráter "dissêmico" dos símbolos, a oposição entre o que os atores sociais mostram de si para os outros e o que sabem de si mesmos - pólos que se alimentam mutuamente. Oposição que não é entre ideal e real, mas do uso de estereótipos de formas e com finalidades distintas (:112-113). Arriscamos assim a aceitar um discurso, seus significados sempre parciais, enrijecidos, motivados por razões práticas, como definidores de uma cultura. Por conseguinte, deixamos de apreender ambigüidades, expectativas, estratégias de interação, articulados a categorias que não apenas designam como moldam realidades. Por sua vez, as categorias analíticas do pesquisador em alguma medida também constroem realidades; a de seu objeto e a sua própria, como analista e como indivíduo também imbuído de cultura. Detenhamo-nos um momento nesse problema.

A exemplo de seus colegas, Gellner mostra-se embaraçado com a busca de um conceito unívoco de patrão, recorrendo em seguida a uma definição pela negativa: a patronagem, enquanto sistema, opõe-se à burocracia. A nte um contexto etnográfico em que se ausentam algumas das características desta última - as quais o autor arrola com maior facilidade - podemos confiar que se trata de um sistema de patronagem. $\mathrm{Na}$ verdade, o procedimento é bastante recorrente, embora nem sempre explícito. A patronagem é definida por intermédio da falta, usualmente traduzida na insuficiente penetração do Estado, na fragilidade das relações centro-periferia, na pouca coesão interna a determinados segmentos sociais ou na incipiência de relações de mercado, em uma comunidade ou em um setor da sociedade. Depreende-se disso que o patrão preenche funções que devem ser cumpridas pelo Estado ou disponibilizadas por um mercado. Dever este que pode ter o triplo sentido de suposição, de recomendação e de previsão. A definição da patronagem pela negativa possui uma conotação crítica inevitável, ainda quando se pondera ser necessário evitar atitudes de condenação (cf. Gellner 1977). A final, também no discurso acadêmico, para retornar a Herzfeld, o que define aquilo que o ser humano deve ser é o sucesso político de um grupo. Por comparação, mesmo que implícita, a este, características divergentes são entendidas como incompletude (1987:49). 
A rgumenta-se que o sistema da patronagem se instala onde não é possível ter acesso direto a recursos ${ }^{5}$. O patrão ocupa, por possuir relações privilegiadas no interior e no exterior de um espaço social, uma posição de intermediário dos seus clientes e os recursos por eles desejados, mesmo que estes venham a implicar uma conexão com um segundo patrão em relação ao qual o primeiro seja cliente. Essas relações tendem a estender-se e formar redes, de tal modo que os papéis de patrão e cliente se definem relacionalmente6.

Presume-se, então, logicamente, que o sistema de patronagem só se sustenta onde $o$ acesso direto a recursos sofre limitações severas. É nesse sentido que uma "burocracia" mais efetiva constituiria o remédio eficaz de extirpação do mal ao qual se opõe por definição. Ou seja, um sistema em que coalizões horizontais, afiliações de classe, substituam relações verticais, assimétricas, entre patrões e clientes. Pois quanto mais obscuras parecerem as operações burocráticas, mais facilmente a patronagem se instala e se mantém. $E$, contrariamente, a máxima racionalização de procedimentos em uma burocracia aperfeiçoada, acredita-se, põe fim aos abusos. A infiltração da patronagem na burocracia significa corrupção. $O$ movimento é similar ao que pretende distinguir elementos culturais orientais na Grécia moderna e os avalia como impuros, contaminador do helenismo grego.

A oposição entre dois sistemas pode comportar um fator temporal. As formas tomadas pelas relações patrão-cliente sucedem-se ou podem retornar transformadas nos processos de modernização das sociedades (cf. e.g. Khalaf 1977: 194; Rassam 1977: 165; Attalides 1977: 153). Dada a correlação entre patronagem e sistemas pré-industriais - subsumida no tema comum aos trabalhos reunidos em Patrons and Clients -, depreende-se um caráter residual de certas práticas ancestrais que se mantêm em sistemas políticos e econômicos em que leis de mercado passam a predominar. Os laços verticais da patronagem se reforçariam onde o sentido de coletividade sucumbe. Daí, por exemplo, o confinamento da patronagem a determinadas esferas, nas quais aparentemente se instituiriam relações dificilmente regidas por outro princípio, dada a escassez intrínseca de determinados recursos ${ }^{7}$, como direitos muito especiais constituídos por certos cargos administrativos (cf. Landé 1977:95-96).

A constatação dessa convivência entre dois modos de orientação das condutas sociopolíticas deu margem a bastante especulação, iniciandose já com a proposição de Wolf (1966), segundo a qual as relações patrãocliente são intersticiais, suplementares e paralelas, tendo como referência as relações institucionais formais. Denota assim um antagonismo fun- 
damental, que permaneceria mesmo na coexistência de dois princípios, uma vez que um se atualizaria nas brechas não preenchidas pelo outro. Observemos que, analiticamente, os termos da dicotomia burocraciapatronagem relacionam-se hierarquicamente. A racionalidade de um sistema não apenas estaria ausente no outro, como deveria ser atingida por este após um processo de modernização. M esmo quando os dois sistemas coexistem, as suas lógicas parecem excluir-se mutuamente, o que pode denotar, na expressão de Herzfeld, um survivalism consistente com a mesma linha analítica: a patronagem subsiste quando e onde quer que a burocracia encontre dificuldade para se instalar.

Se efetuarmos sobre as nossas construções teóricas operações similares à que utilizamos com outros nativos, de modo a extrairmos certos princípios ordenadores, poderemos inferir um encadeamento de oposições binárias subjacentes às nossas construções mentais, de maneira muito similar ao que derivamos das práticas e concepções que observamos no campo, por exemplo, acerca da honra. Não configurarão procedimentos de inclusão e exclusão nossas oposições também passíveis de encadeamento? Os pares, patronagem-burocracia, Mediterrâneo-Europa, comunidade-nação, laços verticais-horizontais, valores de honra-racionalidade - os exemplos podem ser indefinidamente acrescidos - parecem ter pertinência em nossas classificações categóricas, tal como possuem fora da academia. Suas condições de constituição e atualização bem merecem esforços de discernimento e compreensão, tal como aqueles dos grupos sociais que mais costumeiramente estudamos. M esmo porque a fronteira que separa o saber científico do senso comum pode ser bastante porosa, comportando apropriações recíprocas.

Tais pares podem estar implícitos nas descrições etnográficas, uma vez que elas supõem uma atuação, necessariamente seletiva, por parte do pesquisador, ou nas conceptualizações antropológicas. Talvez sejam mais dificilmente percebidos, paradoxalmente, devido a um excesso de intimidade que possuímos, desta vez, com o objeto, por esse motivo menos sujeito às nossas operações de essencialização mais conscientes (embora as essencializações inconscientes estejam presentes aí como em toda parte). Contudo, parecem insinuar-se mais claramente nas descrições e conceptualizações balizadas na falta de certas características. Definir al go pelo que não é conduz muito facilmente a análise no sentido de vislumbrar por antecipação o destino aperfeiçoado da realidade que se pretende expor à luz. Esse pendor profético é particularmente perceptível quando se atribui um caráter residual a um fenômeno. Decorre dessas explicações pela negativa, quase mecanicamente, que as imperfei- 
ções de uma dada realidade podem ser supridas pelo sistema em relação ao qual ela se define como faltosa. A solução apresenta-se não em conclusão, mas em concomitância, se não por antecipação ao problema. Pode estar presente de modo virtual já na definição do sistema, fadado à substituição. A própria instauração da dicotomia torna-se, assim, em si mesma, significativa.

Uma dimensão de valoração insinua-se e parece merecer ser alvo de análise semelhante aos sistemas morais contemplados pela antropologia. O olhar do exótico parece constituir um recurso de construção de nossa própria identidade, de afirmação (ou crítica) de nossos sistemas sociais, econômicos, políticos, morais. Na verdade, a deformação do outro e a construção de si mesmo são, como sustenta Herzfeld (1987) ao longo de seu livro, faces da mesma moeda, produto do mesmo movimento que se registra na antropologia, como em outras ciências, e que é tanto político quanto cognitivo, com conseqüências em ambos os domínios, aliás indissociáveis.

É também nesse sentido que Carrier (1995) concebe um Ocidentalismo, espécie de correlato do Orientalismo acusado por Said, que designa o modo como essencializamos o Ocidente na mesma medida em que produzimos conhecimento acerca daqueles a quem nos opomos. Carrier entende que a partir de M auss, com o Ensaio sobre o Dom, as sociedades melanésias passaram a ser tratadas analiticamente como sistemas de dom. Essa conclusão suscita uma outra, de mesmo nível, que define o Ocidente como sistema individualista de troca alienada. $O$ argumento é flexível a outras adaptações: ao explicarmos sistemas sociais através de valores de honra ou de laços de patronagem não o estaremos fazendo por comparação implícita a um modelo, ocidental, fundamentado em uma racionalidade, dotada do mesmo teor explicativo?

O problema prossegue. As conclusões de M auss, alega Carrier, tornaram-se princípios inquestionáveis, servindo de ponto de partida aos melanesistas a cada nova pesquisa. Outra vez, uma aproximação com o M editerrâneo é possível. Ao ingressar no campo, sabe-se de antemão o que vai merecer os cuidados analíticos, e tudo o que deverá ser filtrado da análise, como residual. O tratamento dado a todas as relações que não encaixam no modelo consiste em descartá-las como periféricas (poderíamos acrescentar intersticiais, suplementares e paralelas). Destarte, as análises reforçam-se umas às outras indefinidamente. Em resultado, uma dicotomia, ou melhor, mais uma série de pares, se acrescenta à nossa cadeia binária. A partir dela, introduzimos mais uma peça no duplo quebra-cabeça que nos define a partir do outro e vice-versa. 
Por meio desses procedimentos analíticos criamos nossa cosmologia acadêmica também merecedora da nossa atenção, não obstante as resistências que essa empresa possa suscitar. De todo modo, ela é um pouco atingida toda vez que empreendemos esforços no sentido de ultrapassar certos lugares comuns da disciplina, que possivelmente possuem mais afinidade com o senso comum do que gostaríamos de admitir. Um passo nessa direção é dado quando passamos a nos debruçar sobre o que tem sido excluído de nossas análises, de nossas mitologias. Isso é válido para o plano teórico e, indissociavelmente, como não se cansa de lembrar Herzfeld, para o etnográfico. Se é no campo que começamos por matar nossos sujeitos a fim de operarmos nossas dissecações analíticas essencializadoras, talvez venha ser aí que a vida Ihes possa ser restituída.

Essa devolução de vida envolve o reconhecimento da atuação de lógicas distintas no mesmo campo social, seja o de uma remota comunidade - doravante emancipada e não tão mais remota - , seja um espaço social do qual nós mesmos tomamos parte. A dimensão política da operação não é desprezível; consiste em concedermos a devida importância, seguindo a sugestão de Herzfeld, à ambigüidade das relações humanas. Mais interessante do que a construção de um modelo mais ou menos estanque segundo o qual interpretamos as variações locais dos comportamentos, é entender a inter-relação das atitudes de orientações distintas, não excludentes nem incompatíveis.

Paradoxalmente, o Mediterrâneo, esse ponto de encontro, se não de fusão, entre nós e outros, parece um ambiente fecundo para o exercício de detectar os acionamentos variáveis de regras sociais divergentes e concomitantes. Exercício ao qual, vale lembrar, os próprios mediterranistas não estiveram insensíveis. As noções de "valores de honra" e de "relações de patronagem" não possuem contornos bem definidos e fixos, de maneira que as práticas a elas associadas escapam às previsões analíticas, bem como às eventuais prescrições sociais. Possivelmente isso tenha estimulado entre os pesquisadores um interesse em detectar códigos de condutas distintos e concomitantes, contextos específicos em que são atualizados e modos variáveis de seu acionamento pelos sujeitos.

$\mathrm{Na}$ condição de membros de uma cultura também categorizamos o mundo, atuamos por adesões e oposições, cognitiva e politicamente. Essa operação se inscreve na nossa dicotomia fundadora, entre nós e os outros que, poderíamos dizer, naturaliza aquilo que bem pode ser entendido como um processo de segmentação não necessariamente fixa, embora passível de ser imobilizada quando o jogo de perspectivas que articula semelhanças e diferenças, conforme circunstâncias sempre variáveis, 
cede lugar a princípios de classificação, de identidade. Como antropólogos, fomos descobrindo e criando ao mesmo tempo nossos primitivos, cada vez mais próximos de nós mesmos, como que subitamente espantados diante de aberrações até pouco antes não notadas, disfarçadas sob uma aparente semel hança, justo quando perplexos, se não desapontados, reconhecemos que o exótico era mais familiar do que esperávamos. O esforço, contudo, não é desprezível nem vão. As aproximações sucessivas também revelam novas faces, movimentos insuspeitos, mundos desconhecidos que afinal percebemos que também habitam em nós mesmos.

Recebido em 11 de novembro de 1998

Reapresentado em 20 de janeiro de 1999

A provado em 10 de fevereiro de 1999

A na Claudia D. R. M arques é mestre pelo Programa de Pós-Graduação em Antropologia Social da UFSC e doutoranda do Programa de Pós- Graduação em Antropologia Social do Museu Nacional/UFRJ . Desenvolve pesquisas sobre cangaço, honra e nomadismo. É autora de Andarilhos e Cangaceiros (no prelo), em colaboração com J orge Luiz M attar Villela e Felipe Brognoli. E-mail: villela@bridge.com.br 


\section{Notas}

* Agradeço a M arcio Goldman, M oacir Palmeira e Federico N eiburg pela atenção e pelos comentários que dispensaram às várias versões do texto e pelo estímulo em produzi-las.

1 "O fato de que, sendo provocado, um cipriota grego, um beduíno e um berbere podem responder 'Eu também tenho um bigode' como o mínimo denominador comum de igualdade entre todos os machos, não aponta necessariamente afinidades entre suas culturas. Nesse contexto, é a comparação da relação machofêmea e dos papéis dos sexos no interior dessas sociedades que apontam tanto para analogias significantes quanto para diferenças igualmente significantes" (Peristiany 1974 [1966]:9).

2 A utilização de um termo cognato da língua para a qual é traduzido, como argumenta Herzfeld (1980), comporta ainda o risco de projeção em um campo semântico nativo de elementos ausentes ali, mas presentes no do cognato, para além da negligência de todas as ambigüidades locais. $O$ grego filotimo e o inglês honor, não designam a mesma coisa. Os campos semânticos locais - Herzfeld analisa variações semânticas em três comunidades distintas - não são completamente coincidentes. Filotimo designa comportamentos públicos apropriados, que variam segundo a localidade e também internamente a elas, conforme circunstâncias específicas que importarão na apreciação pública das atitudes.

3 Os laços entre patrão e cliente podem ser vistos como instrumento de integração social, por exemplo. Para Rassam, mediante eles estabelece-se a ligação entre Estado e grupos locais (1977:159). Gellner vê na patronagem "um sistema, um estilo, um clima moral" (1977:3). Diversamente, Gilsenan argumenta que o que é constatável no âmbito dos comportamentos não pode ser analisado como sistema (1977:180). Estes exemplos ilustram algumas das diferentes perspectivas com que as relações patrão-cliente são tratadas teoricamente em Patrons and Clients.

4 A riqueza das variações semânticas e valorativas do termo signore em uma comunidade podem ser contempladas mediante o exame cuidadoso efetuado por Bailey (1971).

5 Quanto à relevância da escassez de recursos materiais, ver Scott (1977). A disponibilidade material no limite da sobrevivência explicaria a pouca propensão de segmentos mais empobrecidos a arriscar alternativas de produção de recursos.

6 A importância do papel do mediador é depreendida de um conjunto de trabalhos clássicos sobre patronagem (e.g. Wolf 1971[1956]; Boissevain 1966; Foster 1967), que remetem, por conseguinte, mais ou menos explicitamente, à pertinência da oposição entre comunidade e nação ou, mais vagamente, entre o dentro e o fora. O mediador atua justamente nesta fronteira, operando uma ligação 
que dificilmente se faria sem sua intervenção, dado o fechamento das comunidades ou a fragilidade dos aparatos de Estado, de fraca penetração local.

7 Loizos sugere, para o Chipre, em alternativa à noção de escassez de recursos, a de excesso de necessidades promovido pelo próprio processo de modernização (1977:131).

\section{Referências bibliográficas}

ATTALIDES, Michael. 1977. "Forms of Peasant Incorporation in Cyprus During the Last Century". In: E. Gellner \& J . Waterbury (orgs.), Patrons and Clients in Mediterranean Societies. London: Duckworth, Center for Mediterranean Studies of the American Universities Field Staff. pp. 137-155.

BAILEY, F. G. 1971. "What are Signori". In: F. G. Bailey (org.), Gift and Poison. The Politics of Reputation. Oxford: Basil Blackwell. pp. 230-251.

BAROJ A, J ulio Caro. 1974 [1966]. “Honour and Shame: a Cultural Account of Several Conflicts". In: J . G. Peristiany (org.), Honour and Shame. The Values of Mediterranean Society. Chicago: The University of Chicago Press. pp. 79-137.

BOISSEVAIN, J eremy. 1966. "Patronage in Sicily". Man, 1(1):18-33.

BOURDIEU, Pierre. 1974 [1966]. "The Sentiment of Honour in Kabyle Society". In: J . G. Peristiany (org.), Honour and Shame. The Values of Mediterranean Society. Chicago: The University of Chicago Press. pp. 191-241.
CAM PBELL, J ohn K. 1974 [1966]. "Honour and the Devil". In: J. G. Peristiany (org.), Honour and Shame. The Values of M editerranean Society. Chicago: The University of Chicago Press. pp. 139-170.

CARRIER, J ames. 1995. “M aussian Occidentalism: Gift and Commodity Systems". In: J . Carrier (org.), Occidentalis: Images of the West. Oxford: Clarendon Press. pp. 85-108.

FOSTER, G. M. 1967. “The Dyadic Contract: A M odel for the Social Structure of a Mexican Peasant Village". In: J . M. Potter (org.), Peasant Society. A Reader. Boston: Little, Brown. pp. 213-230.

GELLNER, Ernest. 1977. "Patrons and Clients". In: E. Gellner \& J . Waterbury (orgs.), Patrons and Clients in Mediterranean Societies. London: Duckworth, Center for M editerranean Studies of the American Universities Field Staff. pp. 1-6.

GILSENAN, M. 1977. “Against PatronClients Relations". In: E. Gellner \& J. Waterbury (orgs.), Patrons and Clients in M editerranean Societies. London: Duckworth, Center for 
Mediterranean Studies of the A merican Universities Field Staff. pp. 167-183.

HERZFELD, Michael. 1980. “Honour and Shame: Problems in the Comparative Analysis of Moral Systems". Man, 15(2):339-351.

.1984. "The Horns of the Mediterranist Dilemma". American Ethnologist, 11(3):439-454.

. 1985. "Lévi-Strauss in the NationState". J ournal of American Folklore, 98(388):191-208.

1987. Anthropology Through the Looking Glass. Critical Ethnography in the Margins of Europe. New York/Cambridge: Cambridge University Press.

KHALAF, Samir. 1977. “Changing Forms of Political Patronage in Lebanon". In: E. Gellner \&J. Waterbury (orgs.), Patrons and Clients in Mediterranean Societies. London: Duckworth, Center for Mediterranean Studies of the A merican Universities Field Staff. pp. 185-205.

LANDÉ, Carl H. 1977. “N etworks and Groups in Southeast Asia". In: S. W. Schmidt et alii (orgs.), Friends, Followers, and Factions. Berkeley: University of California Press. pp. 74-99.

LoIZOS, Peter. 1977. "Politics and Patronage in a Cypriot Village, 19201970". In: E. Gellner \& J. Waterbury (orgs.), Patrons and Clients in Mediterranean Societies. London: Duckworth, Center for Mediterranean Studies of the American Universities Field Staff. pp. 115-135.

PERISTIANY, J ohn G. 1974 [1966]. “Introduction". In: J. G. Peristiany (org.), Honour and Shame. The Values of Mediterranean Society. Chicago: The University of Chicago Press. pp. 9-18.

PITT-RIVERS, J ulian. 1974 [1966]. “Honour and Social Status". In: J . G. Peri- stiany (org.), Honour and Shame. The Values of M editerranean Society. Chicago: The University of Chicago Press. pp. 19-77.

RASSAM, Amal. 1977. “Al-Taba'iyya: Power, Patronage and Marginal Groups in Northern Iraq. In: E. Gellner $\& J$. Waterbury (orgs.), Patrons and Clients in M editerranean Societies. London: Duckworth, Center for Mediterranean Studies of the A merican Universities Field Staff. pp. 157-166.

SCOTT, J ames. 1977. “Patronage or Exploitation?". In: E. Gellner \& J. Waterbury (orgs.), Patrons and Clients in Mediterranean Societies. London: Duckworth, Center for M editerranean Studies of the American Universities Field Staff. pp. 21-39.

SILVERM AN, Sydel. 1977. "Patronage as Myth". In: E. Gellner \& J. Waterbury (orgs.), Patrons and Clients in Mediterranean Societies. London: Duckworth, Center for M editerranean Studies of the American Universities Field Staff. pp. 7-19.

WATERBURY, J ohn. 1977. "An Attempt to Put Patrons and Clients in Their Place". In: E. Gellner \& J. Waterbury (orgs.), Patrons and Clients in Mediterranean Societies. London: Duckworth, Center for Mediterranean Studies of the American Universities Field Staff. pp. 329-342.

WOLF, E. R.1966. “Kinship, Friendship and Patron-Client Relations in Complex Societies". In: M. Banton (org.), The Social Anthropology of Complex Societies. London: Tavistock, pp. 1-20.

1971 [1956]. "Aspects of Group Relations in a Complex Society: M exico". In: T. Shanin (org.), Peasants and Peasant Societes: Selected Readings. Harmondsworth: Penguin Books. pp. 50-68. 


\section{Resumo}

A antropologia do Mediterrâneo mostra-se um campo fecundo para a discussão do exercício antropológico em geral, pela forma particularmente instigante em que neste campo se confundem objeto e sujeito de um discurso acadêmico. Em Anthropology Through the Looking Glass, Michael Herzfeld salienta aspectos, sobretudo políticos, embutidos em construções conceptuais mediterranistas e antropológicas como um todo. Inspirada em seu trabalho, a autora propõe distinguir alguns pressupostos que parecem orientar nossas práticas, acadêmicas e quotidianas, a partir de certos elementos recorrentes em análises centradas nos temas "mediterrânicos" por excelência da honra e da patronagem. Recorre aos trabalhos reunidos em Patrons and Clients in $\mathrm{Me}$ diterranean Societies e Honor and Shame, referências fundamentais da antropologia do Mediterrâneo, no intuito de reiterar riscos envolvidos nas construções simplificadoras de princípios culturais, com poder explicativo questionável, bem como de enfatizar a importância da pluralidade de elementos locais destacados e de perspectivas adotadas, fatores que podem dificultar simplificações e promover o enriquecimento das concepções que produzimos acerca dos outros e de nós mesmos.

\section{Abstract}

M editerranean anthropology has proven to be a fertile area for discussing anthropological practice in general, due to the particularly novel way in which academic discourse's object and subject merge in the region. In Anthropology Through the Looking Glass, Michael Herzfeld brings to the fore aspects (above all political) embedded in both Mediterranean and anthropological conceptual frameworks. Taking inspiration from his work, the author sets out to delineate some of the presuppositions, which appear to guide our academic and quotidian practices, starting with certain elements prevalent in analyses centering on the emblematically 'M editerranean' themes of honor and patronage. The author turns to the works collected in Patrons and Clients in Mediterranean Societies and Honor and Shame - core texts in Mediterranean anthropology - in order to reiterate the risks involved in reducing cultural principles to simplifying formulas of questionable explanatory power, as well as to emphasize the importance of maintaining plurality in both the local elements selected and the perspectives adopted - factors which can work to inhibit simplifications, promoting instead the enrichment of the concepts we produce concerning others and ourselves. 